\title{
Variation in leaf area density drives the rainfall storage capacity of individual urban tree species
}

Leaf area density affects storage capacity

Mariana D. Baptista ${ }^{\mathrm{a}^{*}}$, Stephen J. Livesley ${ }^{\mathrm{b}}$, Ebadat G. Parmehr ${ }^{\mathrm{c}}$, Melissa Neave ${ }^{\mathrm{a}}$, and Marco Amati ${ }^{\mathrm{a}}$.

${ }^{a}$ Centre for Urban Research, School of Global, Urban and Social Studies, RMIT University, Australia.

melissa.neave@rmit.edu.au

marco.amati@rmit.edu.au

${ }^{\mathrm{b}}$ School of Ecosystem and Forest Sciences, Faculty of Science, Burnley Campus, The University of Melbourne, Burnley VIC 3121, Australia

sjlive@unimelb.edu.au

${ }^{c}$ Department of Geomatics, Faculty of Civil Engineering, Babol Noshirvani University of Technology, Babol, Iran.

parmehr@nit.ac.ir

${ }^{*}$ Correspondent author: Mariana D. Baptista

Centre for Urban Research, School of Global, Urban and Social Studies, RMIT University, 3001, Australia. mariana.diasbaptista@rmit.edu.au

+61399253413

\section{Acknowledgements}

This work was supported by the Australian Research Council Discovery Project, Seeing the good from the trees: remotely sensing the urban forest [DP 150103135].

This is the author manuscript accepted for publication and has undergone full peer review but has not been through the copyediting, typesetting, pagination and proofreading process, which may lead to differences between this version and the Version of Record. Please cite this article as doi: 10.1002/hyp.13255

This article is protected by copyright. All rights reserved. 
We thank Alessandro Ossola and Luis Alberto Orozco Aguilar for their assistance with data collection, and Christopher Szota for assistance with statistical analyses.

\section{Abstract}

A rapid rise of urban population is making cities denser. Consequently, the proportion of impervious surface cover has enlarged, increasing the amount and speed of runoff reaching urban catchment areas, which may cause flash flooding.

Trees play a key role to reduce runoff in the city, as they intercept rainfall and store part of it on their leaves and branches, reducing the amount and speed of water running onto impervious surfaces. Storage capacity will depend on the rainfall event, the climate conditions and tree characteristics and canopy density. These canopy characteristics vary greatly among different species and their phenology. Furthermore, these canopy characteristics can vary greatly among individual trees of the same age, size and species. This study tested how canopy density and leaf characteristics of three different tree species affect storage capacity under simulated rainfall conditions.

Three species were selected (Ulmus procera, Platanus x acerifolia, and Corymbia maculata), each being of the same height and similar canopy dimensions. Storage capacity was measured using a mass balance approach during a 15-minute indoor, simulated rainfall event $(2.54 \mathrm{~mm} / \mathrm{hr})$. Canopy metrics were estimated using a terrestrial laser scanner. Canopy surface area was measured through destructive harvest and leaf/twig/branch scanning. To investigate variations in the canopy leaf density, leaves were systematically removed to create four treatments: full, half, quarter and woody.

This article is protected by copyright. All rights reserved. 
Canopy storage capacity was well correlated to plant surface area $\left(\mathrm{m}^{2}\right)$, plant area index $\left(\mathrm{m}^{2} / \mathrm{m}^{2}\right)$ and plant area density $\left(\mathrm{m}^{2} / \mathrm{m}^{3}\right)$. All analyses indicated $U$. procera as the most efficient species for storing rainfall water within a canopy of equal volume or area index.

Results reveal the complexity of evaluating interception of rainfall by tree canopies. This study contributes to the discipline and practice by distinguishing how variation in the leaf density is important to consider when selecting urban tree species to be planted.

Keywords: interception, plant surface area, plant area index, plant area density, runoff reduction, rainfall simulation. 


\section{Introduction}

By the middle of 2009 the number of inhabitants in cities globally surpassed the number of people in rural areas for the first time (FAO, 2016) and this trend of increasing urban settlement is expected to continue into the foreseeable future. From a hydrological point of view, urbanisation changes the physical characteristics of watersheds and directly affects the timing, quality and quantity of surface flows within them (Armson, Stringer, \& Ennos, 2013). In particular, urbanisation results in an increase in impervious surface area, which reduces the movement of water below ground and increases storm runoff volumes (Arnell, 2002; Wilson, 2016). Depending on the magnitude of the precipitation event, urban storm runoff can cause floods (Wheater \& Evans, 2009) and erosion (Berland et al., 2017), and actively transports urban contaminants into receiving waterbodies (Yang \& Zhang, 2011).

To avoid the problems associated with stormwater runoff, urban centres are often supported by complex engineered drainage networks, consisting of a connected system of surface inlets and underground pipes that are designed to transport the stormwater out of the urban environment as quickly as possible. Unfortunately, many of these urban stormwater drainage networks were constructed when cities were less dense and had fewer impervious surfaces, and before climate change was widely assumed to increase future storm intensities (Wilson, 2016). As such, many urban stormwater drainage systems are currently functioning close to, or at, capacity, placing their associated urban centres at a higher risk of repeated flooding (Moore, Gulliver, Stack, \& Simpson, 2016). Upgrading and re-engineering the drainage network of a city is both costly and technically challenging, and this encourages the consideration of alternatives to help reduce runoff, such as increasing urban green spaces and vegetation cover (Armson et al., 2013; Ossola, Hahs, \& Livesley, 
2015; Zhang, Xie, Li, \& Wang, 2015; Zhang, Xie, Zhang, \& Zhang, 2012), and implementing water sensitive urban design technologies (Lloyd, 2001; Roy et al., 2008).

Trees have the potential to play an important role in modifying urban hydrological cycles as their leaves, branches and stems directly intercept and temporarily store water during precipitation events (Livesley, McPherson, \& Calfapietra, 2016). Some of this water is lost as evaporation, reducing its contribution to stormwater runoff, and some is delayed, reducing peak discharges (Levia, Keim, Carlyle-Moses, \& Frost, 2011; Xiao \& McPherson, 2002). Armson et al. (2013) for example, identified that surfaces beneath trees in the urban region of Manchester, UK had 60\% less runoff than comparable surfaces without trees. As such, trees have the potential to play an important role in reducing stormwater impacts in urban environments.

The process whereby trees capture precipitation is referred to as interception and is known to vary depending upon the tree species under consideration. Research has shown that characteristics, such as bark roughness, branch inclination, and leaf roughness and angle, directly affect tree canopy interception rates, and determine the maximum and minimum canopy storage capacity $\left(\mathrm{C}_{\max }\right.$ and $\mathrm{C}_{\min }$ ) (Li et al., 2016; Van Stan, Levia, \& Jenkins, 2014). Smoother bark and leaves, as well as branch and leaf angle of orientation are known to influence stemflow rate and throughfall rates (Holder \& Gibbes, 2016; Li et al., 2016; Livesley, Baudinette, \& Glover, 2014; Xiao \& McPherson, 2011).

An important characteristic of trees that greatly determine their capacity to intercept and store water is the overall surface area of the canopy made up of individual leaves (Aston, 1979; Li et al., 2016; Xiao \& McPherson, 2016). As such, leaf area index (LAI), or the surface area of leaves included in one square meter of ground area $\left(\mathrm{m}^{2} / \mathrm{m}^{2}\right)$, is commonly used to represent the ability of a tree to intercept and store water (Aston, 1979; Barbier, 
Balandier, \& Gosselin, 2009; Goebes, Bruelheide, Härdtle, \& Kröber, 2015; Li et al., 2016; Xiao \& McPherson, 2016; Yang, Endreny, \& Nowak, 2011). Although the areal extent of leaves is clearly important for interception, less well understood is the influence of plant area density (PAD) or the total leaf and stem area per unit volume of canopy $\left(\mathrm{m}^{2} / \mathrm{m}^{3}\right)$. Many urban trees grow in confined street canyons that limit lateral canopy growth and are frequently pruned to avoid wires and poles or to facilitate traffic movement. This may change the ratio of leaf to stem matter and make PAD an important parameter to consider in interception analyses. Little however is known about how changes in leaf density affect the amount of water stored in trees over time.

The aim of this research is to analyse how changes in leaf area affects surface water storage capacity, and to identify the associated proportional contribution that is made by woody surfaces (stems and branches). This research involves evaluating and comparing the interception of rainfall by three tree species that are commonly used in urban landscapes in Melbourne, Australia. Specific objectives are to: (1) measure and compare canopy area metrics (including plant surface area, plant area index and plant area density) for each species; (2) measure maximum and minimum water storage capacities $\left(C_{\max }\right.$ and $C_{\min }$, respectively) for each species; (3) estimate the effect of varying leaf area density on tree water storage capacities; and (4) compare leaf and woody surface area contributions to canopy storage for each species. Understanding how architectural differences between species and trees influence water storage will help inform urban forest managers about which species to plant if reducing urban stormwater runoff is a strategic priority (Xiao \& McPherson, 2011). Similarly, the information will demonstrate how tree pruning or different levels of leaf loss (e.g., through storms, herbivory or drought) or canopy senescence with age will influence the interception and storage of precipitation. 


\section{Materials and Methods}

Three tree species were investigated in this study, with four replicate trees examined for each species, resulting in a total of 12 trees being measured. The included species were London Plane (Platanus x acerifolia), English Elm (Ulmus procera), and Spotted Gum (Corymbia maculata), which were selected based on their common use in urban parks and street plantings in Melbourne, Australia (Table 1). For the remainder of this paper the individual Corymbia trees are referred to as $\mathrm{CM} 1$ to $\mathrm{CM} 4$, the Ulmus trees are referred to as UP1 to UP4 and the Platanus trees are referred to as PA1 to PA4.

The 12 study trees were grown in $100 \mathrm{~L}$ pots. All trees had their basal stem diameter (BD), tree height $(\mathrm{H})$, canopy height $(\mathrm{CH})$, canopy projected area $(\mathrm{CA})$, canopy volume $(\mathrm{CV})$, leaf area (LA—method explained below), and branch area (BA—method explained below) measured. These were then used to calculate the following parameters: leaf area index ( $\mathrm{LAl})$ or the surface area of leaves included in one square meter of ground area-calculated as LA/CA; branch area index (BAI) or the surface area of branches included in one square meter of ground area-calculated as BA/CA; plant surface area (PSA) or the total surface area covered by a plant-calculated as BA + LA; plant area index (PAI) or the surface area covered by a plant in one square meter of ground area-calculated as PSA/CA; and plant area density (PAD) or the total leaf and stem area per unit volume of canopy-calculated as PSA/CV. Trees presented comparable basal stem diameters (BD) ranging from 6.2 to 9.7 $\mathrm{cm}$, and initial canopy volumes (CV) that ranged from $5.61 \mathrm{~m}^{3}$ to $7.99 \mathrm{~m}^{3}$ (Table 2).

\section{Rainfall simulation}

To measure the volume of water stored by a canopy, each tree was subjected to multiple rainfall simulation experiments. To avoid the effects of wind and direct solar 
irradiance, these experiments were undertaken indoors, which kept precipitation rates constant and uniform, and ensured an appropriate rain drop size distribution as defined by Knasiak, Schick, \& Kalata (2007). The rainfall simulator consisted of seven full-cone, wideangle nozzles (Model TG-SS4.3W, Spraying System Co., Wheaton, IL, USA) placed $2 \mathrm{~m}$ apart in a hexagonal arrangement, and controlled by a single pressure valve (Fig. 1). The nozzles were positioned on a frame with a pulley system that allowed height above the tree canopies to be adjusted.

Prior to the simulation runs, nozzle calibration tests were performed to investigate the spatial and temporal variability of the simulated rainfall at different precipitation rates $(2.5$, 5.1, 7.6, and $10.2 \mathrm{~mm} / \mathrm{hr}$ ). Each nozzle was tested over a ten second period following the work of Kibet et al. (2014) and Knasiak, Schick, \& Kalata (2007). To test spatial uniformity of the rainfall 172 containers (diameter of $80 \mathrm{~mm}$ ) were placed at ground level ( $4.7 \mathrm{~m}$ below the nozzles) in a grid with an equal spacing distance of $0.25 \mathrm{~m}$. Coefficients of variation (CV) were then calculated for the water received in the containers for each test event to assess uniformity. The best uniformity was found for the $2.54 \mathrm{~mm} / \mathrm{hr}$ precipitation rate, which required the rainfall simulator to operate at mains pressure of $67 \mathrm{kPa}$, producing a flow rate of $1.6 \mathrm{~L} / \mathrm{min}$. A rainfall rate of $2.54 \mathrm{~mm} / \mathrm{hr}$ for 15 minutes is classified as Very Frequent in Melbourne, with in excess of 12 exceedances per year (Bureau of Meteorology, 2017).

Rainfall uniformity was also checked at different heights above the ground $(0.5,1,1.5$ and $2 \mathrm{~m})$. The best uniformity $(\mathrm{CV}<25 \%)$ was achieved at $2 \mathrm{~m}$. As the rainfall simulator frame could be raised to a maximum height of $4.7 \mathrm{~m}$, the trees in this study were limited to a height of $2.7 \mathrm{~m}$ so that the rainfall was uniform once it intercepted the top of a canopy. To accommodate this, all trees were top-trimmed to ensure they did not exceed a height of 2.7 $\mathrm{m}$. 


\section{Water storage capacity measurements}

Before the start of each rainfall simulation experiment, the tree being investigated was placed on a balance (150 kg capacity, $20 \mathrm{~g}$ resolution) to continuously measure mass. Water storage (i.e., interception) was calculated as the change in mass balance of the tree during exposure to rainfall. To prevent stemflow or throughfall entering the pot and therefore contributing to an increase in measured tree mass, each pot was carefully covered with plastic sheets that directed throughfall outside the measurement system (Figure 1c). A small plastic roof was bonded to the tree stem above these plastic sheets with silicone adhesive. These roofs were made of smooth plastic and steeply pitched to avoid ponding and direct stem flow away from the pot to the outside of the measurement system. Therefore, the number of drops held on the small roof at any one time was not considered to have a significant impact on storage variability.

Once a tree was placed on the balance, the rainfall simulator was run for a period of 15 minutes and tree weight was recorded every 5 seconds. Maximum interception storage $\left(C_{\max }\right)$ was measured as the increase in weight observed at the end of the 15 minutes of rainfall simulation (Figure 2). Measurements continued to be taken for another 15 minutes following the end of the simulated rainfall, ensuring that throughfall and stemflow had ceased. The water remaining in the canopy at this point was identified as representing the minimum interception storage $\left(\mathrm{C}_{\min }\right)$ (Figure 2).

\section{Sequential leaf removal to reduce canopy leaf density}

Canopy water storage was initially measured using rainfall simulation for each of the twelve trees (x4 C. maculata, x4 P. acerifolia, x4 U. procera) with their canopies intact (Full canopy). The trees were then given at least 24 hours to dry, and then every second leaf was 
removed from all branches, reducing the canopy leaf density from $100 \%$ to approximately $50 \%$ (Half canopy). Canopy water storage was then re-measured using rainfall simulation on all twelve trees again, but at Half canopy. After a period of drying, every second leaf of the half canopy was removed to reduce canopy leaf density from 50\% to 25\% (Quarter canopy). Canopy water storage was then remeasured using rainfall simulation for all twelve trees, but this time at Quarter canopy. Finally, all the remaining leaves were removed and canopy water storage of the bare tree architecture (Woody) of all twelve trees was measured. In total, this resulted in 48 rainfall simulations, 12 for each level of canopy leaf density $(100 \%$, $50 \%, 25 \%$ and $0 \%)$.

The first half of removed leaves had their areas directly measured using a leaf area meter (LI-3100 Area Meter, Li-cor, Lincoln, USA). The leaves were initially oven dried at $60^{\circ} \mathrm{C}$ for 48 hours after which they leaf dry mass was determined, and a ratio leaf area by leaf mass was calculated for each tree. All remaining leaves were oven dried and had their leaf area calculated by this ratio. This produced a calculation for total leaf area (LA) for each tree.

After the final simulations, the woody material for each tree was collected and divided into two groups depending on their diameter class: $\geq 1 \mathrm{~cm}$ or $<1 \mathrm{~cm}$. Branches in the larger diameter class had their lengths and diameters measured manually. Branches with a diameter of less than $1 \mathrm{~cm}$ were measured using a photo scanning method. First, branches were placed on a light box with a camera (ELMO HV-5100XG Visual Presenter, and ELMO TT-12 Document Camera, Plainview, NY, USA) and photographed against the light to capture their exact shadow. A metal rod of known diameter and length was placed in every photo to provide a quality check on the size of the branches. The pictures were then printed and scanned to obtain monochromatic images that could be accurately analysed using the 
$\pi / 2$ analysis of the Delta-T SCAN@ software (Delta-T Devices Ltd., Burnwell, England), which returned estimates of branch length, area and volume. This resulted in the calculation of total branch area (BA) for each tree.

Terrestrial Laser Scanning (TLS)

The canopies for every full canopy tree were also assessed using a hand-held laser scanner, ZEB1 (GeoSLAM Ltd., Nottingham, UK) that consists of a swinging head which shoots multiple laser beams to scan horizontally and vertically with a $270^{\circ}$ field of view (GeoSLAM, 2015). These scans produced a point cloud for every tree, at each canopy condition (full, half, quarter and woody). A concave hull method was then used to calculate tree canopy metrics, such as canopy project area (CA) and canopy volume (CV), from the point cloud (Figure 3). To undertake the scans, the target tree was placed in a space with an unobstructed radius of $2 \mathrm{~m}$. The trees were then scanned by walking around them three times at a distance of 1-2 $\mathrm{m}$ with the scanning device positioned a few centimetres from the body to deliver optimum point cloud accuracy and density. To make point density consistent, a random down sampling approach was utilised. In this approach, points closer together than $2 \mathrm{~cm}$ were counted as a single point. A statistical denoising algorithm was then applied to remove the extra points from the point cloud. To apply this method, the neighbourhood distance was defined as $10 \mathrm{~cm}$. Points within this window were used to estimate statistical parameters, whereas points with a weak connection to the sample points were identified as noise and removed from the point cloud. The point cloud data manipulations were performed using CloudCompare 2.6.2 software.

\section{Statistical Analyses}

Statistical analyses were undertaken to determine the best predictor of water storage capacity and to validate the relationships between tree metrics and interception parameters. 
Analyses of covariance (ANCOVA) were performed to identify differences between species, with $\mathrm{C}_{\max }$ or $\mathrm{C}_{\min }$ values held as the dependent variable and the tree characteristics of plant surface area (PSA), plant area index (PAI), and plant area density (PAD) as the covariates. These analyses indicated some errors in the calculations of $\mathrm{C}_{\min }$ for $\mathrm{CM} 1$ and $\mathrm{CM} 2$, which recorded negative differences between the Full and Half canopy data for $C_{\min }$, and for UP2, which returned a negative difference between the Half and Quarter canopy data for $C_{\min }$. As a consequence, these samples were removed from the dataset. A post-hoc Tukey test was used to validate statistical differences between species and all statistical analyses were performed on RStudio 1.0.153.

\section{Results}

Range and variation in canopy surface area metrics

Of the three species considered in this study, $P$. acerifolia recorded the largest leaf area (LA), branch area (BA), plant surface area (PSA) and plant area density (PAD). In contrast, C. maculata recorded the lowest metrics for all of the canopy characteristics considered in this study (Table 2). Ulmus procera generally sat between the other two species, although it recorded the largest leaf area index (LAl) and the largest plant area index (PAI). These differences were all statistically significant at $p \leq 0.05$.

Impact of tree species and leaf reduction on canopy storage

Average estimates for both $\mathrm{C}_{\max }$ and $\mathrm{C}_{\min }$ were highest for $U$. procera (UP), followed by $P$. acerifolia (PA), and C. maculata (CM) for all density classes (Figure 4, Table 3 ). The one exception to this was the Woody class for $P$. acerifolia (PA), and C. maculata (CM) which had the same values for $C_{\max }(0.06 \mathrm{~mm})$ and $C_{\min }(0.01 \mathrm{~mm})$. Unsurprisingly, the average values for $\mathrm{C}_{\max }$ and $\mathrm{C}_{\min }$ both decreased as canopy leaf density was reduced. After 
the first leaf removal phase (Half canopy), canopy storage rates had declined by $12 \%, 55 \%$ and $50 \%$ for C. maculata, P. acerifolia, and U. procera, respectively. By the end of the second leaf removal phase (Quarter canopy), canopy storage rates had declined by 38\%, $76 \%$, and 53\%, for C. maculata, P. acerifolia, and U. procera, respectively. Finally, when all leaves were off (Woody), canopy storage rates had decreased by $62 \%, 90 \%$, and $87 \%$ for $C$. maculata, $P$. acerifolia, and $U$. procera, respectively.

Relations between canopy water storage and surface area metrics

The ANCOVA analyses returned several significant differences between the tree species for both $\mathrm{C}_{\max }$ and $\mathrm{C}_{\min }$ (Table 4). The relationship between $\mathrm{C}_{\max }$ and PSA was significantly different $(p \leq 0.05)$ for all three tree species. Notably, at the same PSA, $U$. procera is intercepting and storing almost twice as much water as the other two tree species, as indicated by the $b$ correlation coefficient (Figure $5 a$, Table 4). For $\mathrm{C}_{\max }$ against both PAI and PAD, there were no significant differences between the trends observed for $P$. acerifolia and $C$. maculata, but $U$. procera was significantly different to the other two species (Figures $5 c$ and $5 e$, Table 4).

A similar pattern of no difference between $P$. acerifolia and C. maculata was observed for $C_{\min }$ against both PSA and PAD (Figures $5 b$ and $5 f$, Table 4). However, for $C_{\min }$ against PAI there was no significant difference between the results returned for the three species (Figure $5 d$, Table 4). Collectively, these results indicate that $U$. procera has a significantly greater water storage capacity $\left(\mathrm{C}_{\max }\right.$ and $\left.\mathrm{C}_{\min }\right)$ than $P$. acerifolia and $C$. maculata for most canopy surface metrics.

Importance of leaf area and woody surface area for canopy storage

When comparing the $\mathrm{C}_{\min }$ values for the Full canopy data to the Woody (no leaf) data, the results indicated that the majority of water was stored by the leaf surfaces of these 
species rather than the woody fabric (Table 5). However, the importance of water interception and storage by woody components of the canopy varied with tree species. For $U$. procera and $P$. acerifolia water storage on woody components represented approximately $10 \%$ of the total canopy stored volume, whereas for C. maculata approximately $40 \%$ of the water volume was stored on the surface area of the woody components.

\section{Discussion}

Range and variation in canopy surface area metrics

The canopy surface area metrics of PSA, PAI and PAD vary between the three tree species (Table 2) investigated in this study. In this research, plant surface area (PSA) was directly influenced by the size and quantity of the leaves and branches on a tree, regardless of their spatial distribution. For example, the size of $P$. acerifolia leaves is likely to have contributed to this species having a greater overall PSA $\left(9.74 \mathrm{~m}^{2}\right)$ than either $U$. procera $\left(7.65 \mathrm{~m}^{2}\right)$ or C. maculata $\left(4.56 \mathrm{~m}^{2}\right)$ (Table 1$)$. Interestingly, $U$. procera also returned a relatively large PSA, despite having smaller leaves. However, the total recorded leaf area (LA) for this species indicated that it had a high number of leaves per tree and this resulted in its relatively high PSA. Corymbia maculata recorded both the lowest total leaf area (LA) and branch area (BA) in this study but also had a comparatively large canopy area (CA) and therefore it recorded the lowest PSA.

In contrast to PSA, the results for PAI (plant area index) indicate the importance of the arrangement of foliar elements within the canopy to this variable (Bréda, 2003). Ulmus procera had the smallest average canopy area of the three species considered in this study but a relatively large total leaf area, leading to a denser, closer canopy. As such, and despite not having the highest PSA, $U$. procera recorded the highest plant area index (PAI), which in 
this sense can be interpreted as a measure of the density of the leaves (and branches) in a compressed two-dimensional plane. Once again, Corymbia maculata with its relatively sparse canopy recorded the lowest PAI.

Finally, PAD (plant area density), which describes the vertical distribution of leaf density, has been used in forest studies because it is considered to provide a better indication of actual plant-atmosphere interactions than measures such as leaf area index (Lalic \& Mihailovic, 2004). Although calculating PAD in isolated canopies is easier than in interconnected forested canopies this approach has not been used much for describing urban trees (Lalic \& Mihailovic, 2004; Meir, Grace, \& Miranda, 2000) and therefore there is scope to consider the use of this parameter in the current research. In this study, values of PAD were greater for $P$. acerifolia (1.24), followed by $U$. procera (1.14) and $C$. maculata $(0.82)$

For urban foresters, these results reveal that an increase (or decrease) in canopy plant area density can vary between species, which has implications for ecological and hydrological functioning, particularly through canopy water storage and the generation of impervious runoff. In urban street canyons where tree canopy growth is likely to be restricted by height restrictions or obstructions (awnings, telegraph/power cables), and by lateral spread (between buildings and vehicle roadways), trees with denser canopies are likely to perform the ecological function of rainfall interception and water storage better than species with more open canopies.

In summary, in this study Platanus $x$ acerifolia had the highest PSA (plant surface area) and PAD (plant area density) but not the highest PAI (plant area index). In contrast, $C$. maculata recorded the lowest values for all three of the canopy surface area metrics considered in this research. These findings indicate that these three metrics have slightly 
different relational trends with species, suggesting that the outcomes of predictive models that incorporate them will be somewhat dependent on species choice and the metric that was used to describe them.

Canopy water storage and its relation to plant surface area metrics

Prior work has demonstrated the importance of the intercepting surface area to storage capacity (e.g., Aston, 1979; Li et al., 2016; Xiao \& McPherson, 2016) and the present research supports these findings. In this study, U. procera with a Full canopy recorded an average $C_{\min }$ of $0.38 \mathrm{~mm}$, which means that this species stored 0.38 litres of rainfall per square meter of canopy cover, under a rainfall intensity of $2.54 \mathrm{~mm} \mathrm{hr}^{-1}$. For the same conditions, P. acerifolia stored 0.29 litres, and C. maculata stored 0.06 litres. Li et al. (2016) observed similar $C_{\min }$ values ranging between $0.13 \mathrm{~mm}( \pm 0.02)$ to $0.41 \mathrm{~mm}( \pm 0.08)$ for four different tree species under simulated rainfall intensity of $10 \mathrm{~mm} \mathrm{hr}^{-1}$. Variation in the canopy storage capacity of urban trees, or any tree, is generally attributed to differences in leaf area and morphology (Xiao \& McPherson, 2016), although little work has been done to investigate the relationship between this and the canopy volume metrics considered in this study.

The results of the rainfall simulation experiments were slightly unexpected given that P. acerifolia had a larger canopy area (CA), a larger total leaf area (PSA) and large leaves with serrated edges that might be likely to facilitate greater water adherence to a leaf (Holder \& Gibbes 2016; Goebes et al. 2015). Not surprisingly, this species retained more canopy water than C. maculata which has waxy pendulous leaves and smoother bark surfaces that promote the rapid drainage of water from the canopy and which may partially explain the small water storage capacity of this tree species (Carlyle-Moses \& Schooling, 2015; Livesley et al., 2014; Park \& Cameron, 2008; Crockford \& Richardson, 2000). Despite its leaf 
morphology however, P. acerifolia stored less canopy water than $U$. procera which also had rough leaves but a lower canopy area and total leaf area. This suggests that leaf and/or branch characteristics have an important role to play in explaining the water retention capacity of the study trees.

Further, C. maculata drained more water than would be normally accounted for by PAI. For pendulous trees such as C. maculata, where the foliage and branches are not parallel to the ground surface, the angle of the leaves and branches need to be factored in to better calculate the tree benefit. These findings therefore suggest that although PAI is commonly used in ecological benefits modelling, the actual benefit a particular species provides may be overestimated when this parameter is used because it does not account for leaf and branch inclination (Stadt \& Lieffers, 2000).

Canopy surface areas are constantly changing according to stage of tree maturity (natural canopy senescence, deciduous phenology), environmental stress conditions (drought, heat, storm), and management practices (pruning, lopping, pollarding) (Bréda, 2003; Jonckheere et al., 2004). While many of these changes are hard to predict, deciduous phenology is not and when $U$. procera and $P$. acerifolia drop their leaves in winter there will be a large reduction in storage capacity rates of up to $90 \%$ (Table 3). Extending this over the course of one year, deciduous trees are estimated to intercept approximately $14 \%$ less water than evergreen species (Barbier et al., 2009). However, our results suggest that this is not born out for the selected species. Based on monthly aerial photographs in Melbourne, $U$. procera and $P$. acerifolia are bare for a period of five months each year. Considering monthly rainfall is relatively consistent between seasons in Melbourne (Bureau of Meteorology, 2017), and based on calculations comparing $C_{\max }$ and $C_{\min }$ for the Full and Woody canopy conditions, both the deciduous species, $P$. acerifolia and $U$. procera, would store $57 \%$ and 
$87 \%$ more water, respectively, in one year than the evergreen species, C. maculata, which has a far smaller plant area density and highly hydrophobic leaves and branches.

Although $\mathrm{C}_{\max }$ and $\mathrm{C}_{\min }$ both represent measures of canopy interception, relationships between them and canopy metrics are somewhat complex. $\mathrm{C}_{\max }$ is a dynamic metric, measured under rainfall conditions where drops of water are hitting the leaves and bouncing or falling off them (Li et al., 2016; Xiao et al., 2000). On the other hand, $\mathrm{C}_{\min }$ is the static interception storage and is measured after excess rainfall has drained off the leaf (Li et al., 2016). The relationship between the species considered in this study and $\mathrm{C}_{\max }$ and $\mathrm{C}_{\min }$ suggests they vary slightly depending on the choice of canopy surface metric and the species under consideration. For example, $U$. procera recorded statistically higher $\mathrm{C}_{\max }$ and $C_{\min }$ values for all canopy surface metrics except PAI for $C_{\min }$. The rougher leaves of $U$. procera may be effective at slowing down the water and ensuring a larger maximum storage for a given leaf area. As such, the storage capacity of this species is a not only a function of leaf area but also of leaf roughness. In contrast, $P$. acerifolia and $C$. maculate returned statistically similar trends between the canopy surface metrics and $C_{\max }$ and $C_{\min }$, with the exception of PSA and $C_{\max }$. Once again, these findings indicate the need to individually consider species responses to particular canopy surface metrics. It is worth noting that although previous research also points to the importance of varying rainfall characteristics on canopy storage capacity (Klamerus-Iwan, 2015; Li et al., 2016), the use of a constant rainfall intensity in this study indicates that variations observed in $\mathrm{C}_{\max }$ and $\mathrm{C}_{\min }$ reflect variations in canopy area metrics only.

Comparing leaf and woody surface area to canopy water storage: contrasts with previous work

This article is protected by copyright. All rights reserved. 
This study indicates that leaves (arrangement and morphology) are important with regard to intercepting rainfall on trees. However, these findings are slightly in contrast to those of Li et al. (2016) who tested $C_{\max }$ and $C_{\min }$ for four tree species under different rainfall intensities over 60 minutes. They found the average $C_{\max }$ was 2.6 times larger for branches than for leafy surfaces. In the present study, the $C_{\max }$ and $C_{\min }$ values indicated that leaves collected considerably more water than woody tree parts for all three species. The only exception to this was $\mathrm{C}_{\min }$ for $C$. maculata for which the Woody storage was higher than the leaf storage. These results may reflect the nature of the particular species that were considered in our study. Ulmus procera and $P$. acerifolia both have branch inclinations of greater than $45^{\circ}$, and all three species have smooth bark, influencing a rapid draining off of water.

In addition, C. maculata, as well other species of the same genus, are well-known for their high investment in producing woody biomass and have leaves that are pendulous and covered in wax to reduce water loss via transpiration which helps them survive in drier regions (Hallam, 1970). This combination of conditions also reduces the volume of water that is stored on both the leaves and the branches of these trees.

Finally, it is possible that the decision to use juvenile trees may have underestimated the contribution of the woody parts to water storage. As trees mature their bark tends to roughen and they grow larger branches, both of which are likely to capture more water than occurs on juvenile trees (Barbier et al., 2009). Further research into the study species using mature trees is required to determine whether this is the case.

The potential contribution of canopy water storage to reduce stormwater runoff

To illustrate the potential implications of this research a simple but practical application has been undertaken to calculate the impact of urban tree species selection on 
runoff reduction in a theoretical streetscape. The hypothetical scenario was a $50 \mathrm{~m}$ long street (5.5 wide) covered in asphalt with two sidewalks each $2.5 \mathrm{~m}$ wide, generating a total impervious area of $525 \mathrm{~m}^{2}$ (50 m long $\times 10.5 \mathrm{~m}$ wide). The objective for this street is reduce stormwater runoff volumes by planting four trees using the three study species of $U$. procera, P. acerifolia and C. maculata.

A $5 \mathrm{~mm} \mathrm{hr} r^{-1} 1$ hour duration design rainfall event received across the $525 \mathrm{~m}^{2}$ surface area will generate $2625 \mathrm{~L}$ of water. Assuming that the first $1 \mathrm{~mm}$ of incident rainfall is stored on the surface and does not become runoff (Boyd, Bufill, \& Knee, 1993), the total runoff generated from this surface will be $2100 \mathrm{~L}$. This represents the approximate amount of water running off to the storm water drainage system and associated waterways, but any tree placed on this impervious surface will act to catch some of that rainfall. For the purpose of this exercise, four trees each with a $10 \mathrm{~m}$ wide canopy are placed in the sidewalk, producing a combined tree canopy area of $192 \mathrm{~m}^{2}$. Excluding the fraction of the canopy that is not sheltering for impervious public area (38.8\%), the canopy area will receive a total of $961.3 \mathrm{~L}$ of rainfall (with the remaining rainfall volume falling on the impervious surface outside the tree canopies). Based on the $C_{\min }$ values observed in this study, the water storage of Corymbia maculata, Platanus $x$ acerifolia and Ulmus procera would be approximately 114 , 415 , and $545 \mathrm{~L}$, respectively. Therefore, for a $5 \mathrm{~mm}$ rainfall event this would be a $5 \%, 20 \%$ and $26 \%$ reduction in runoff, respectively.

Despite being an important part of rainfall partitioning for mature isolated trees (Carlyle-Moses and Schoolling, 2015), water loss via stem flow (SF) has not being counted in the calculations because the example assumes that the SF water is running directly onto an impervious surface, and counting as runoff water. However, in a realistic setting, further research could integrate information on the presence or absence of permeable surfaces at 
or near tree bases, so as to acknowledge another significant ecosystem service that trees provide in streetscapes (Carlyle-Moses and Schoolling, 2015).

Although the percentage runoff reductions would vary depending upon rainfall characteristics (duration, intensity, antecedent conditions, etc.), this small activity highlights the potential role that tree canopies can provide through interception and canopy storage and points to their capacity to help mitigate flood risk and reduce the occurrence of the 'urban stream syndrome' in cities.

\section{Conclusions}

Urban trees have the potential to play a larger and more directed role in the mitigation of runoff, although to date they have not been greatly factored into the management of urban hydrology. However, tree metrics, such as leaf, branch and canopy areas, are key factors in understanding the process of water storage in a canopy. Morphologic differences between species influence these measures directly and express their differences in tree architecture.

To understand the canopy interception process, rainfall simulation experiments were used to estimate the maximum and minimum canopy storage capacity $\left(C_{\max }\right.$ and $C_{\min }$, respectively) for three tree species commonly used as street trees in the city of Melbourne, Australia. The selected study species were Ulmus procera, Platanus $\mathrm{x}$ acerifolia, and Corymbia maculata. For each species, four individual trees were subject to four rainfall simulation events, with the trees being sequentially defoliated between events. This allowed for comparisons of $\mathrm{C}_{\max }$ and $\mathrm{C}_{\min }$ between species and under various degrees of foliation (from having a Full canopy to being complete devoid of leaves).

The results of this study indicate that common tree canopy area metrics, such as PSA (plant surface area), PAI (plant area index) and PAD (plant area density) show varying 
responses to rainfall storage depending on species and extent of defoliation. Ulmus procera routinely stored more water thein either $P$. acerifolia or $C$. maculata, even though $P$. acerifolia had higher average PSA and PAD metrics. This finding indicates the importance of understanding how these surface area metrics vary between species and of identifying how each individual metric impacts on rainfall storage by trees. As such, when planning urban forests for flood mitigation, managers need to take into account important differences between species, including leaf and branch area, roughness and angle.

This study also revealed that the contribution of woody material to storage capacity varies between species and can be quite significant, although in most cases the trees in this study stored most of their water on their leaves. This finding is very important when considering the balance of evergreen and deciduous trees because deciduous trees remain without leaf for a long period. This may suggest that evergreen trees will always have a greater storage capacity (over time) than their deciduous counterparts, but in this study the evergreen species (C. maculata) stored less water over the course of a year than the other two species, both of which are deciduous.

This research suggests that urban foresters should consider the density of leaves per canopy volume as well as leaf and woody surface characteristics to promote storage of rainfall if this is a desired ecosystem function from urban tree plantings. They must also keep in mind that at any life stage, trees may suffer a reduction of their canopy due to pathogen attacks, insect herbivory or climate impacts, e.g., severe drought or heat waves. Such reductions in canopy surface area will directly affect their water storage capacity.

This article is protected by copyright. All rights reserved. 


\section{References}

Armson, D., Stringer, P., \& Ennos, a. R. (2013). The effect of street trees and amenity grass on urban surface water runoff in Manchester, UK. Urban Forestry and Urban Greening, 12(3), 282-286.

Arnell, N. (2002). Hydrology and Global Environmental Change (1st ed.). Person Education.

Aston, a. R. (1979). Rainfall interception by eight small trees. Journal of Hydrology, 42(3-4), 383-396.

Barbier, S., Balandier, P., \& Gosselin, F. (2009). Influence of several tree traits on rainfall partitioning in temperate and boreal forests: A review. Annuals of Forest Science, 66, 602 (11 pp.).

Berland, A., Shiflett, S. A., Shuster, W. D., Garmestani, A. S., Goddard, H. C., Herrmann, D. L., \& Hopton, M. E. (2017). The role of trees in urban stormwater management. Landscape and Urban Planning.

Boyd, M. J., Bufill, M. C., \& Knee, R. M. (1993). Pervious and impervious runoff in urban catchments. Hydrological Sciences Journal, 38(6), 463-478.

Bréda, N. J. J. (2003). Ground-based measurements of leaf area index: A review of methods, instruments and current controversies. Journal of Experimental Botany, 54(392), 2403-2417.

Bureau of Meteorology. (2017). Intensity-Frequency-Duration: Design rainfalls. Retrieved October 8, 2017, from http://www.bom.gov.au/water/designRainfalls/ifd/

Carlyle-Moses, D. E., \& Schooling, J. T. (2015). Tree traits and meteorological factors influencing the initiation and rate of stemflow from isolated deciduous trees.

Hydrological Processes, 29(18), 4083-4099.

Crockford, R. H., \& Richardson, D. P. (2000). Partitioning of rainfall into throughfall, stemflow and interception: effect of forest type, ground cover and climate. Hydrological Processes, 14, 2903-2920.

FAO. (2016). Guidelines on urban and peri-urban forestry. Rome.

Fletcher, T. D., Andrieu, H., \& Hamel, P. (2013). Understanding, management and modelling of urban hydrology and its consequences for receiving waters: A state of the art. Advances in Water Resources, 51, 261-279.

GeoSLAM. (2015). Survey in motion: ZEB1 - handheld mobile mapping system. Retrieved from www.geoslam.com/hardware-products/zeb1/

Goebes, P., Bruelheide, H., Härdtle, W., \& Kröber, W. (2015). Species-Specific Effects on 
Throughfall Kinetic Energy in Subtropical Forest Plantations Are Related to Leaf Traits and Tree Architecture. PLoS One, 10(6), 1-13.

Hallam, N. D. (1970). Growth and regeneration of waxes on the leaves of Eucalyptus. Planta, 93(3), 257-268.

Holder, C. D., \& Gibbes, C. (2016). Influence of leaf and canopy characteristics on rainfall interception and urban hydrology. Hydrological Sciences Journal, (August).

Jonckheere, I., Fleck, S., Nackaerts, K., Muys, B., Coppin, P., Weiss, M., \& Baret, F. (2004). Review of methods for in situ leaf area index determination Part I. Theories, sensors and hemispherical photography. Agricultural and Forest Meteorology, 121, 19-35.

Kibet, L. C., Saporito, L. S., Allen, A. L., May, E. B., Kleinman, P. J. A., Hashem, F. M., \& Bryant, R. B. (2014). A Protocol for Conducting Rainfall Simulation to Study Soil Runoff. Journal of Visualized Experiments, (86).

Klamerus-Iwan, A. (2015). Rainfall parameters affect canopy storage capacity under controlled conditions. Forest Research Papers, 75(4).

Knasiak, K., Schick, R. J., \& Kalata, W. (2007). Multiscale Design of Rain Simulator. In 20th Annual Conference on Liquid Atomization and Spray Systems (pp. 1-9). Chicago.

Lalic, B., \& Mihailovic, D. T. (2004). An Empirical Relation Describing Leaf-Area Density inside the Forest for Environmental Modeling. Journal of Applied Meteorology, 43, 641645.

Levia, D. F., Keim, R. F., Carlyle-Moses, D. E., \& Frost, E. E. (2011). Throughfall and stemflow in wooded ecosystems. In D. F. Levia, D. E. Carlyle-Moses, \& T. Tanaka (Eds.), Forest hydrology and biogeochemistry, Synthesis of past research and future directions (pp. 425-443).

Li, X., Xiao, Q., Niu, J., Dymond, S., Doorn, N. S. Van, Yu, X., ... Li, J. (2016). Processbased rainfall interception by small trees in Northern China and crown structure characteristics. Agricultural and Forest Meteorology, 218-219, 6573.

Livesley, S. J., Baudinette, B., \& Glover, D. (2014). Rainfall interception and stem flow by eucalypt street trees - The impacts of canopy density and bark type. Urban Forestry and Urban Greening, 13, 192-197.

Livesley, S. J., McPherson, G. M., \& Calfapietra, C. (2016). The Urban Forest and Ecosystem Services: Impacts on Urban Water, Heat, and Pollution Cycles at the Tree, Street, and City Scale. Journal of Environment Quality, 45(1), 119-124.

Lloyd, S. D. (2001). Water Sensitive Urban Design in the Australian Context. Water Sensitive Urban Design conference: Synthesis of a conference held 30 - 31 August 2000, 
Melbourne, Australia. Melbourne.

Meir, P., Grace, J., \& Miranda, A. C. (2000). Photographic method to measure the vertical distribution of leaf area density in forests. Agricultural and Forest Meteorology.

Moore, T. L., Gulliver, J. S., Stack, L., \& Simpson, M. H. (2016). Stormwater management and climate change barvulnerability and $c$ contexts. Climatic Change, 491-504.

Ossola, A., Hahs, A. K., \& Livesley, S. J. (2015). Habitat complexity influences fine scale hydrological processes and the incidence of stormwater runoff in managed urban ecosystems. Journal of Environmental Management, 159, 1-10.

Park, A., \& Cameron, J. (2008). The influence of canopy traits on throughfall and stemflow in five tropical trees growing in a Panamanian plantation. Forest Ecology and Management, 255, 1915-1925.

Roy, A. H., Wenger, Æ. S. J., Fletcher, ÆE. T. D., Walsh, ÆE. C. J., Ladson, A. R., Shuster, ÆE. W. D., ... Brown, R. R. (2008). Impediments and Solutions to Sustainable , Watershed-Scale Urban Stormwater Management United States. Environmental Management, 344-359.

Stadt, K. J., \& Lieffers, V. J. (2000). MIXLIGHT: A flexible light transmission model for mixedspecies forest stands. Agricultural and Forest Meteorology, 102, 235-252.

Van Stan, J. T., Levia, D. F., \& Jenkins, R. B. (2014). Forest canopy interception loss across temporal scales: Implications for urban greening initiatives. The Professional Geographer, 0, 1-11.

Wheater, H., \& Evans, E. (2009). Land use, water management and future flood risk. Land Use Policy, 26(SUPPL. 1), 251-264.

Wilson, W. G. (2016). Stormwater: A resource for scientists, engineers, and policy makers (1st ed.). Chicago: The University of Chicago Press.

Xiao, Q., \& McPherson, E. G. (2016). Surface Water Storage Capacity of Twenty Tree Species in Davis, California. Journal of Environmental Quality, 45(1), 188-198.

Xiao, Q., Mcpherson, E. G., Forest, U., Ustin, S. L., Grismer, M. E., \& Abstract, A. (2000). A new approach to modeling tree rainfall interception. Journal of Geophysical Research, 105(16), 173-29.

Xiao, Q., \& McPherson, G. E. (2002). Rainfall interception by Santa Monica's municipal urban forest. Urban Ecosystems, 6, 291-302.

Xiao, Q., \& McPherson, G. G. (2011). Rainfall interception of three trees in Oakland, California. Urban Ecosystems, 14(June), 755-769. 
Yang, J., \& Zhang, G. (2011). Water infiltration in urban soils and its effects on the quantity and quality of runoff. Soils Sediments, (11), 751-761.

Yang, Y., Endreny, T. A., \& Nowak, D. J. (2011). iTree-Hydro: Snow hydrology update for the urban forest hydrology model. Journal of the American Water Resources Association, 47(6), 1211-1218.

Zhang, B., Xie, G., Li, N., \& Wang, S. (2015). Effect of urban green space changes on the role of rainwater runoff reduction in Beijing , China. Landscape and Urban Planning, $140,8-16$.

Zhang, B., Xie, G., Zhang, C., \& Zhang, J. (2012). The economic benefits of rainwater-runoff reduction by urban green spaces

JocAkrcatsef study in Beijing , China.

Environmental Management, 100, 65-71.

This article is protected by copyright. All rights reserved. 


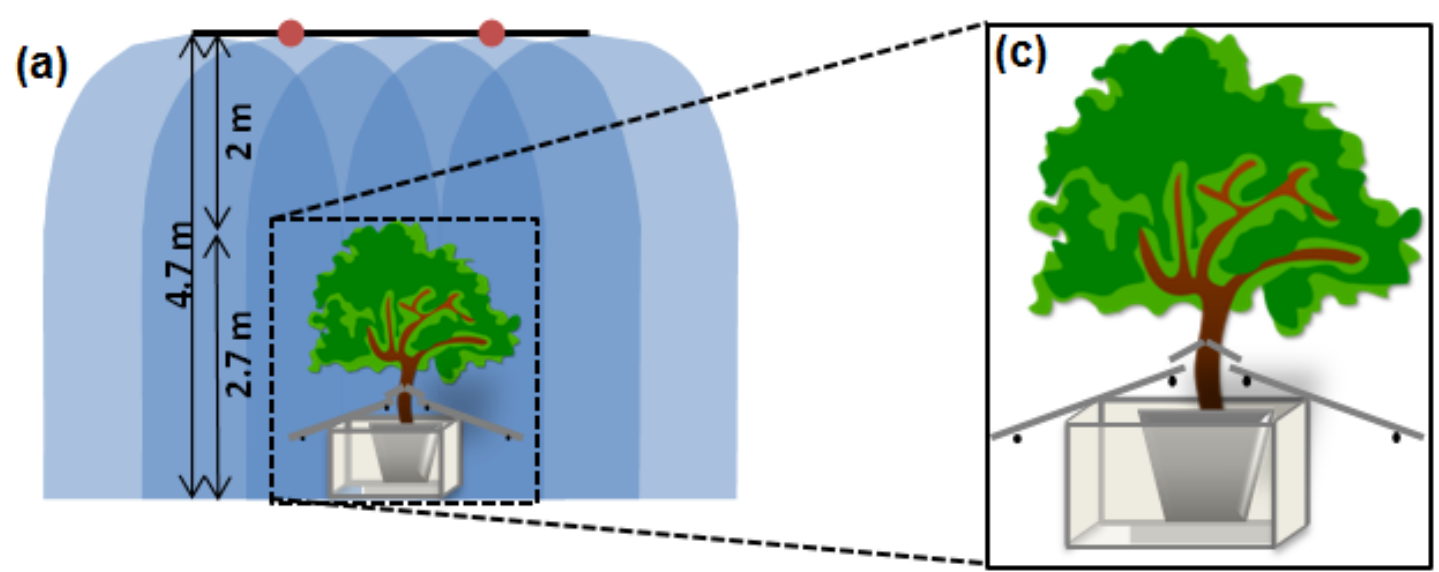

(b)

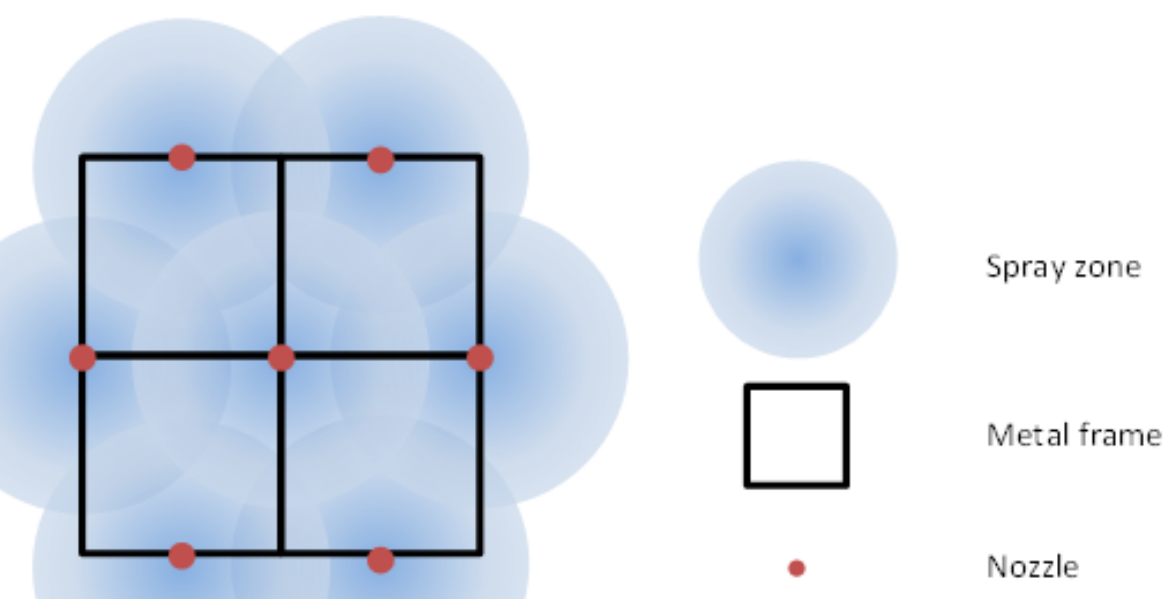

Figure 1- Rainfall simulator cross-section view (a); Top view of simulator spray zone (b); small plastic roof small plastic roof attached to the tree and plastic sheets to prevent water to drip into the pot (c).

This article is protected by copyright. All rights reserved. 


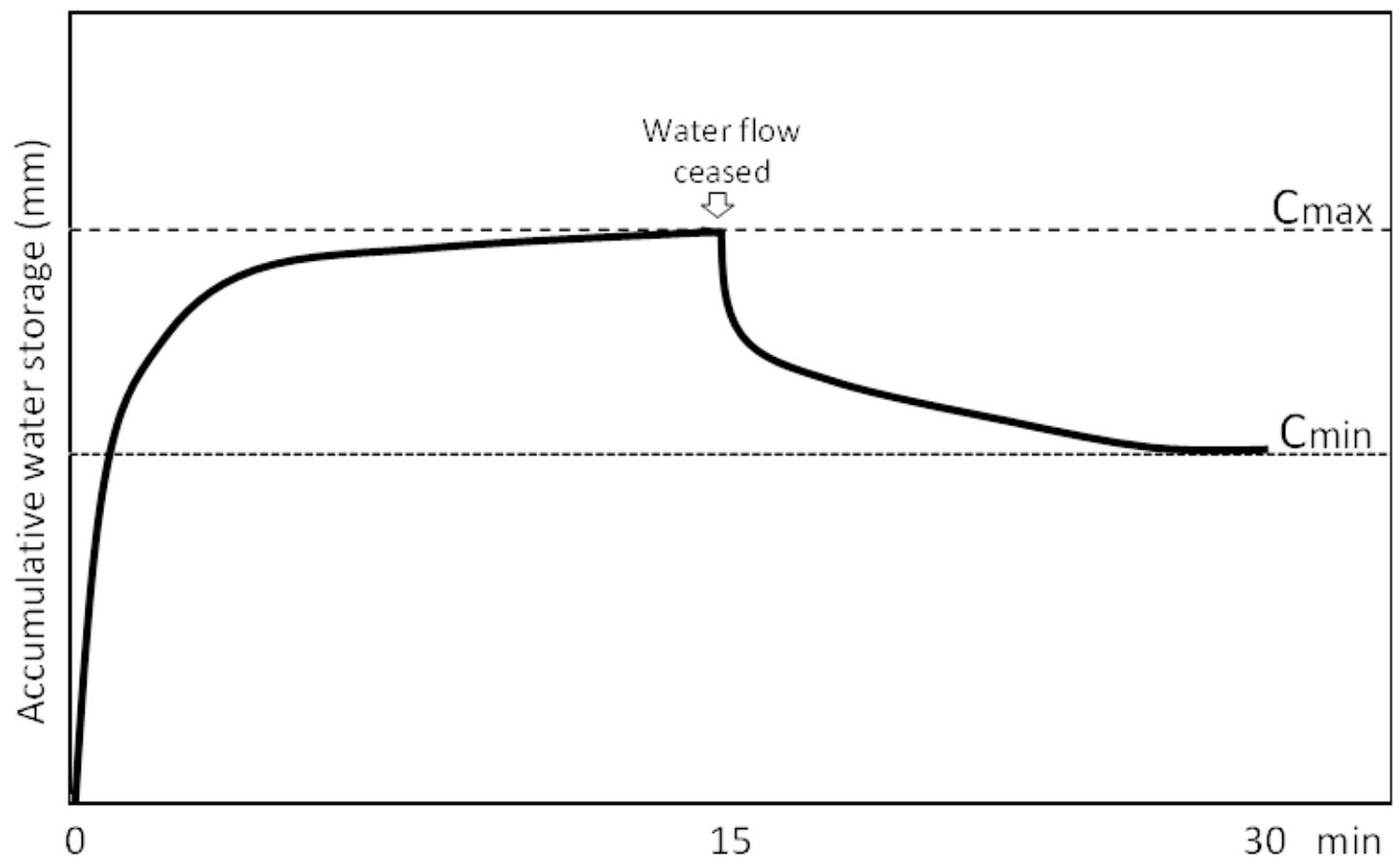

Figure 2 - Dynamic of water storage capacity of tree canopies during $\mathbf{3 0}$ min after a simulated rainfall of 15minutes. Maximum storage capacity $\left(C_{\max }\right)$ is the maximum amount of water intercepted after a 15 minutes rainfall. Minimum storage capacity $\left(C_{\min }\right)$ is the amount of water effectively stored in the canopy (and posteriorly evaporated) after 15 minutes of dripping. 
(a)
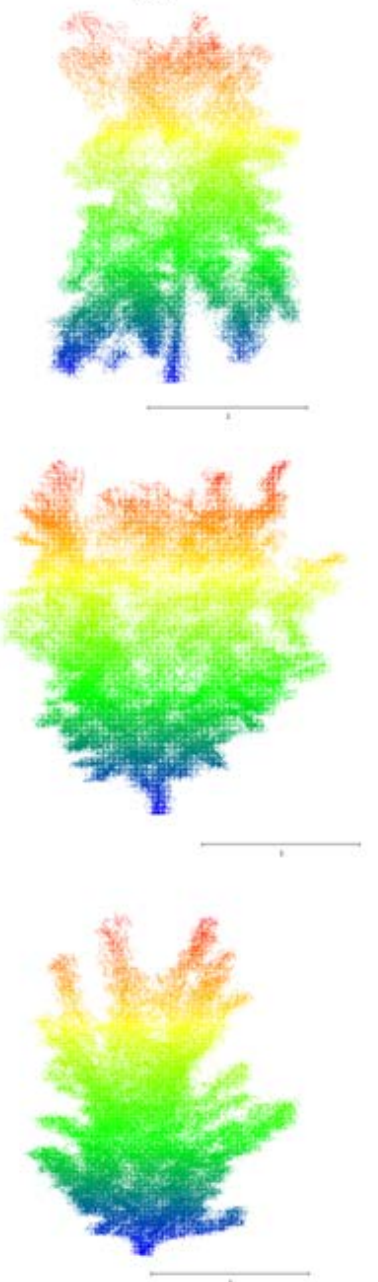

(b)
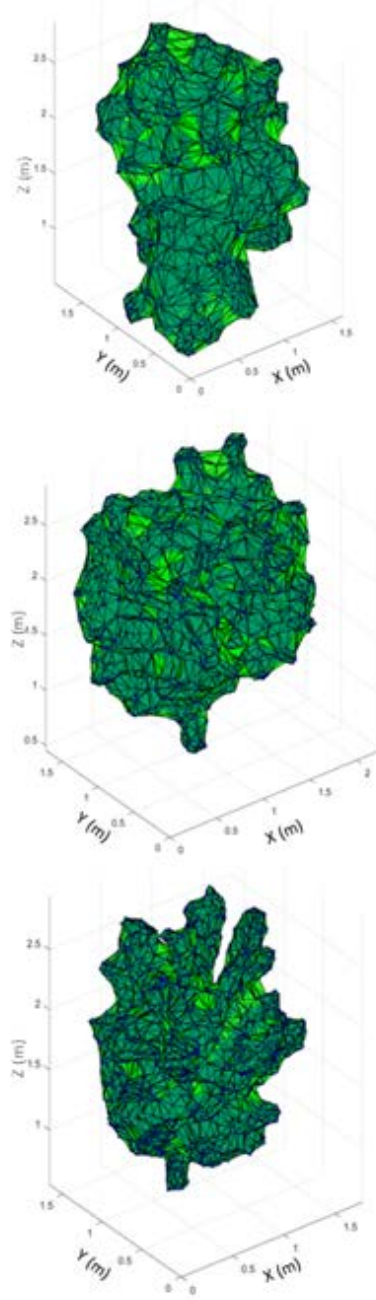

(c)
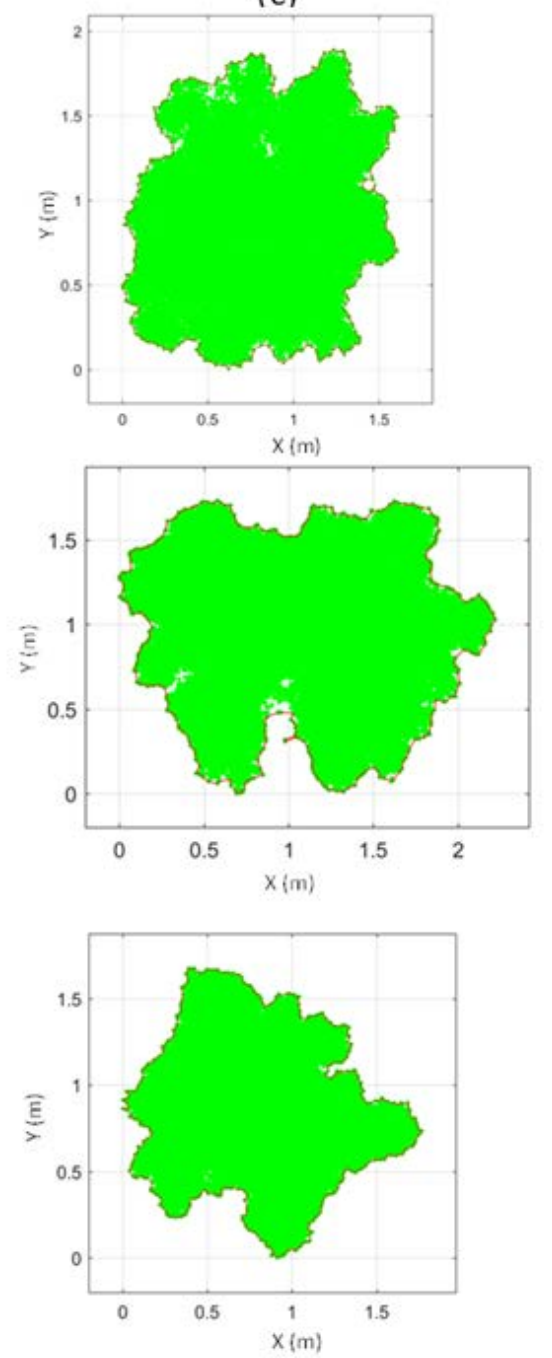

Figure 3 - Tree canopy point cloud of C. maculata (CM1), P. acerifolia (PA1) and U. procera (UP1), from top to bottom respectively (a). Calculated canopy volume by concave hull method (b). Canopy projected area calculated by concave hull method (c). 

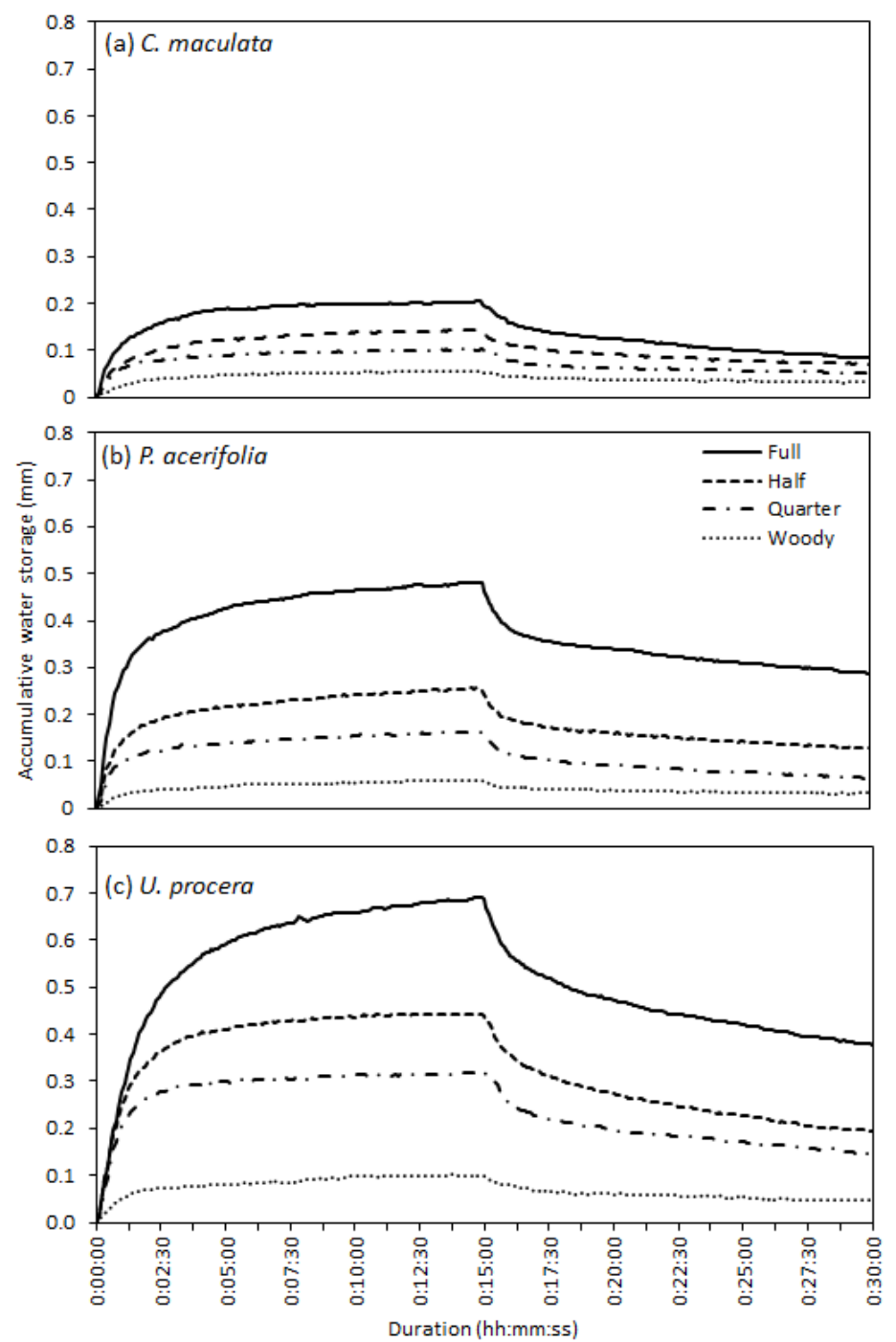

Figure 4 -Cumulative tree canopy water storage for Corymbia maculata, Platanus $\mathrm{x}$ acerifolia, and UImus procera during 15 minutes of simulated rainfall (rate $\mathrm{mm} / \mathrm{hr}$ ) and 15 minutes after the rainfall ceased. Canopy water storage was measured for full (100\%) foliage (solid line), then half (50\%) foliage canopy (dashed line), quarter (25\%) foliage canopy (dot-dash line) and finally with all leaves removed (0\%) and the woody stem and branch architecture only (dotted line). Each line is the mean of four replicate tree measures $(\mathrm{N}=4)$. 

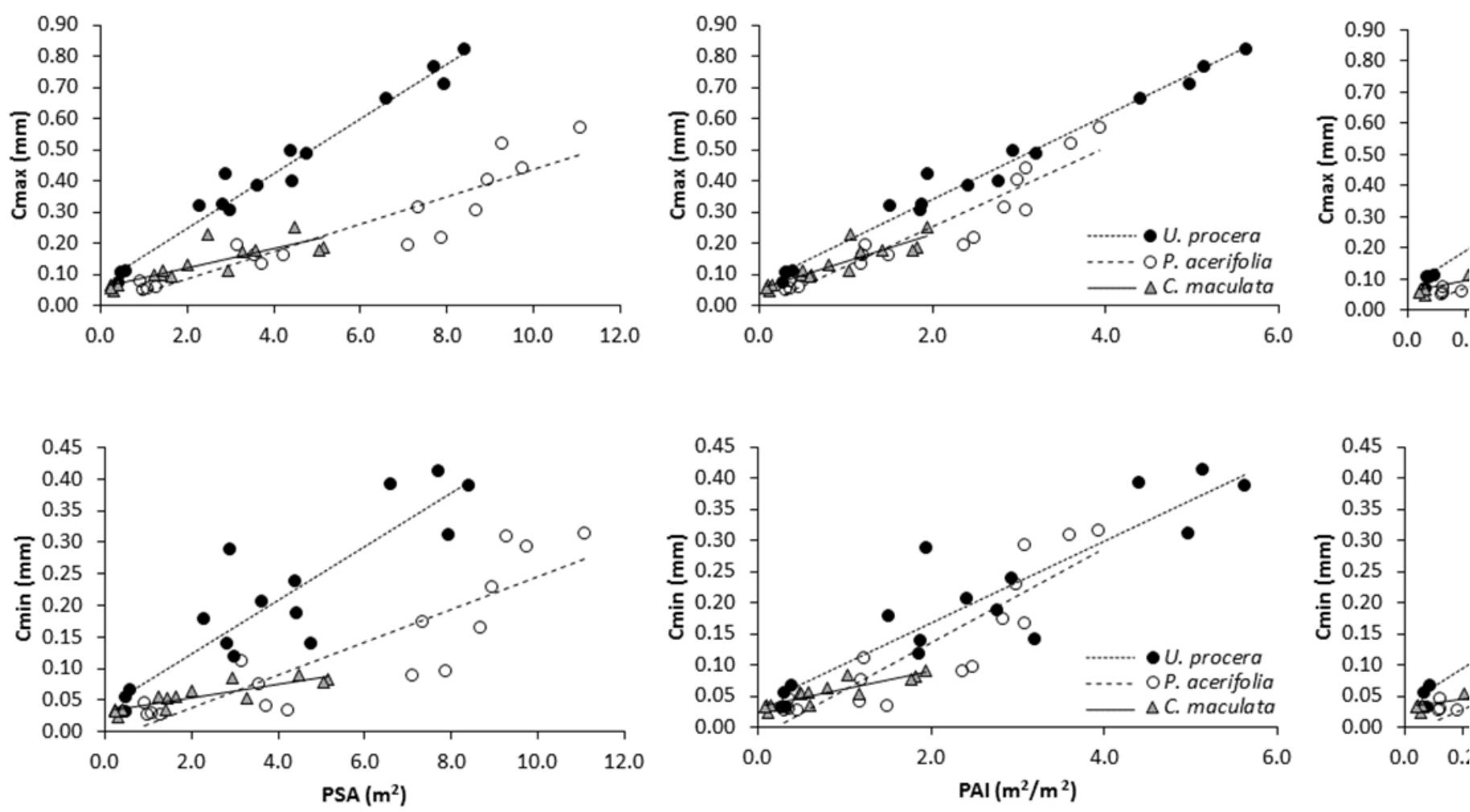

Figure 5 - Linear regression analyses between canopy surface metrics (plant surface area [PSA]; plant area index $[\mathrm{PAI}]$; and plant area density $[\mathrm{PAD}]$ ) and interception parameters (maximum $\left[\mathrm{C}_{\max }\right]$ and minimum $\left[\mathrm{C}_{\mathrm{min}}\right]$ storage capacity) for three tree species (Ulmus procera; Platanus $\mathrm{x}$ acerifolia; and Corymbia maculata. a) PSA x $\mathrm{C}_{\max }$; b) PSA x $\mathrm{C}_{\min }$; c) PAI x $\mathrm{C}_{\max }$; d) PAI x $\mathrm{C}_{\min }$; e) PAD x $\mathrm{C}_{\max }$; and f) PAD $\times$ $\mathrm{C}_{\min }$ 
Table 1 - Species characteristics

\begin{tabular}{|c|c|c|c|c|}
\hline Common name / Species & Leaf habit & Leaf profile & Bark & Street treet profile \\
\hline $\begin{array}{c}\text { Spotted gum } \\
\text { Corymbia maculata }\end{array}$ & Evergreen & & & \\
\hline $\begin{array}{l}\text { London plane } \\
\text { Platanus } \times \text { acerifolia }\end{array}$ & Deciduous & & & \\
\hline $\begin{array}{l}\text { English elm } \\
\text { Ulmus procera }\end{array}$ & Deciduous & & & \\
\hline
\end{tabular}

This article is protected by copyright. All rights reserved. 
Table 2 - Measured metrics of studied trees. (BD=Basal diameter; $\mathrm{H}=$ Tree height; $\mathrm{CH}=\mathrm{Canopy}$ height; $C A=C a n o p y$ projected area; $C V=C a n o p y$ volume; $L A=$ Total leaf area; $L A I=L e a f$ Area Index; $B A=b r a n c h$ area; $\mathrm{BAI}=$ branch area index; $\mathrm{PSA}=$ Plant surface area; $\mathrm{PAI}=\mathrm{Plant}$ area index; $\mathrm{PAD}=\mathrm{Plant}$ area density)

\begin{tabular}{|c|c|c|c|c|c|c|c|c|c|c|}
\hline $\begin{array}{l}\text { Tree } \\
\text { ID } \\
\end{array}$ & Species & $\mathrm{BD}(\mathrm{cm})$ & $\begin{array}{c}\mathbf{H} \\
(\mathrm{m})\end{array}$ & $\begin{array}{l}\mathrm{CH} \\
\text { (m) }\end{array}$ & $\begin{array}{c}\text { CA } \\
\left(m^{2}\right)\end{array}$ & $\begin{array}{c}\text { CV } \\
\left(\mathrm{m}^{3}\right)\end{array}$ & $\begin{array}{c}\text { LA } \\
\left(\mathrm{m}^{2}\right)\end{array}$ & LAI & $\mathrm{BA}\left(\mathrm{m}^{2}\right)$ & BAI \\
\hline CM1 & & 8.28 & 2.70 & 1.35 & 2.32 & 4.93 & 4.27 & 1.84 & 0.23 & 0.10 \\
\hline $\mathrm{CM} 2$ & Spotted gum & 7.80 & 2.70 & 1.12 & 2.50 & 5.06 & 3.28 & 1.31 & 0.29 & 0.12 \\
\hline $\mathrm{CM} 3$ & Corymbia maculata & 9.71 & 2.70 & 1.50 & 2.81 & 6.97 & 4.73 & 1.68 & 0.41 & 0.15 \\
\hline $\mathrm{CM} 4$ & & 8.12 & 2.70 & 1.15 & 2.84 & 5.49 & 4.81 & 1.69 & 0.23 & 0.08 \\
\hline Mean & & 8.47 & 2.70 & 1.28 & 2.62 & 5.61 & 4.27 & 1.63 & 0.29 & 0.11 \\
\hline PA1 & & 7.80 & 2.70 & 1.98 & 2.58 & 7.53 & 8.38 & 3.25 & 0.90 & 0.35 \\
\hline PA2 & London Plane & 8.91 & 2.70 & 2.15 & 3.00 & 8.96 & 7.85 & 2.62 & 1.03 & 0.34 \\
\hline PA3 & Platanus $x$ acerofolia & 9.39 & 2.70 & 2.07 & 2.82 & 7.05 & 9.78 & 3.47 & 1.28 & 0.45 \\
\hline PA4 & & 7.80 & 2.70 & 2.00 & 3.17 & 8.42 & 8.76 & 2.76 & 0.98 & 0.31 \\
\hline Mean & & 8.47 & 2.70 & 2.05 & 2.89 & 7.99 & 8.69 & 3.02 & 1.04 & 0.36 \\
\hline UP1 & & 7.64 & 2.70 & 2.09 & 1.60 & 7.55 & 7.44 & 4.65 & 0.49 & 0.30 \\
\hline UP2 & English Elm & 7.48 & 2.70 & 2.05 & 1.49 & 6.57 & 7.89 & 5.30 & 0.49 & 0.33 \\
\hline UP3 & Ulmus procera & 7.64 & 2.70 & 1.82 & 1.50 & 6.52 & 7.12 & 4.75 & 0.57 & 0.38 \\
\hline UP4 & & 6.21 & 2.70 & 1.93 & 1.50 & 6.35 & 6.20 & 4.13 & 0.39 & 0.26 \\
\hline Mean & & 7.24 & 2.70 & 1.97 & 1.52 & 6.75 & 7.17 & 4.71 & 0.49 & 0.32 \\
\hline
\end{tabular}


Table $3-C_{\max }$ and $C_{\min }$ results (mm), mean and standard deviation (STD) for different species (CM: $C$. maculata; PA: P. acerifolia; UP: U. procera) in different leaf density.

\begin{tabular}{|c|c|c|c|c|c|c|c|c|}
\hline \multirow[b]{3}{*}{ Tree ID } & \multicolumn{8}{|c|}{ Canopy density classes } \\
\hline & \multicolumn{2}{|l|}{ Full } & \multicolumn{2}{|l|}{ Half } & \multicolumn{2}{|l|}{ Quarter } & \multicolumn{2}{|l|}{ Woody } \\
\hline & $\mathrm{C}_{\max }(\mathrm{mm})$ & $\mathrm{C}_{\min }(\mathrm{mm})$ & $\mathrm{C}_{\max }(\mathrm{mm})$ & $\mathrm{C}_{\min }(\mathrm{mm})$ & $\mathrm{C}_{\max }(\mathrm{mm})$ & $\mathrm{C}_{\min }(\mathrm{mm})$ & $\mathrm{C}_{\max }(\mathrm{mm})$ & $\mathrm{C}_{\min }(\mathrm{mm})$ \\
\hline CM1 & 0.25 & 0.09 & 0.22 & & 0.10 & 0.03 & 0.06 & 0.03 \\
\hline $\mathrm{CM} 2$ & 0.18 & & 0.13 & 0.06 & 0.10 & 0.06 & 0.05 & 0.02 \\
\hline CM3 & 0.19 & 0.08 & 0.17 & 0.05 & 0.11 & 0.05 & 0.06 & 0.04 \\
\hline CM4 & 0.18 & 0.08 & 0.11 & 0.08 & 0.10 & 0.06 & 0.06 & 0.03 \\
\hline Mean \pm STD & $0.20 \pm 0.03$ & $0.08 \pm 0.01$ & $0.16 \pm 0.04$ & $0.07 \pm 0.01$ & $0.10 \pm 0.01$ & $0.05 \pm 0.01$ & $0.06 \pm 0.01$ & $0.03 \pm 0.00$ \\
\hline PA1 & 0.52 & 0.31 & 0.32 & 0.17 & 0.20 & 0.11 & 0.08 & 0.05 \\
\hline PA2 & 0.40 & 0.23 & 0.20 & 0.09 & 0.16 & 0.08 & 0.06 & 0.03 \\
\hline PA3 & 0.57 & 0.32 & 0.31 & 0.17 & 0.16 & 0.04 & 0.06 & 0.03 \\
\hline PA4 & 0.44 & 0.29 & 0.22 & 0.10 & 0.14 & 0.04 & 0.05 & 0.03 \\
\hline Mean \pm STD & $0.49 \pm 0.07$ & $0.29 \pm 0.03$ & $0.26 \pm 0.05$ & $0.13 \pm 0.04$ & $0.16 \pm 0.02$ & $0.07 \pm 0.03$ & $0.06 \pm 0.01$ & $0.03 \pm 0.01$ \\
\hline UP1 & 0.51 & 0.31 & 0.40 & 0.19 & 0.31 & 0.12 & 0.11 & 0.06 \\
\hline UP2 & 0.83 & 0.39 & 0.49 & 0.14 & 0.42 & & 0.11 & 0.03 \\
\hline UP3 & 0.77 & 0.41 & 0.50 & 0.24 & 0.33 & 0.14 & 0.11 & 0.07 \\
\hline UP4 & 0.67 & 0.39 & 0.39 & 0.21 & 0.32 & 0.18 & 0.07 & 0.03 \\
\hline Mean \pm STD & $0.69 \pm 0.12$ & $0.38 \pm 0.04$ & $0.44 \pm 0.05$ & $0.19 \pm 0.02$ & $0.34 \pm 0.04$ & $0.15 \pm 0.03$ & $0.10 \pm 0.01$ & $0.05 \pm 0.01$ \\
\hline
\end{tabular}


Table 4 - Summary for linear regressions parameters (x: independent variable; y: dependent variable; a: intercept; b: slope; $\mathbf{R}^{2}$ : coefficient of determination; Sign: Tukey's result at $95 \%$ of significance)

\begin{tabular}{|c|c|c|c|c|c|c|c|}
\hline Species & $x$ & $y$ & $a$ & $b$ & $\mathrm{R}^{2}$ & Sign.(95\%)* & Figure \\
\hline C. maculata & PSA & $\mathrm{C}_{\max }$ & 0.060 & 0.031 & 0.718 & $a$ & \\
\hline P. acerifolia & PSA & $\mathrm{C}_{\max }$ & 0.000 & 0.044 & 0.855 & $b$ & $5 a$ \\
\hline U. procera & PSA & $\mathrm{C}_{\max }$ & 0.075 & 0.088 & 0.974 & $\mathrm{c}$ & \\
\hline C. maculata & PSA & $\mathrm{C}_{\min }$ & 0.033 & 0.011 & 0.769 & a & \\
\hline P. acerifolia & PSA & $\mathrm{C}_{\min }$ & -0.015 & 0.026 & 0.773 & a & $5 b$ \\
\hline U. procera & PSA & $\mathrm{C}_{\min }$ & 0.038 & 0.043 & 0.817 & $\mathrm{~b}$ & \\
\hline C. maculata & PAI & $\mathrm{C}_{\max }$ & 0.055 & 0.088 & 0.808 & $a$ & \\
\hline P. acerifolia & PAl & $\mathrm{C}_{\max }$ & 0.002 & 0.127 & 0.892 & a & $5 c$ \\
\hline U. procera & PAI & $C_{\max }$ & 0.074 & 0.134 & 0.982 & $\mathrm{~b}$ & \\
\hline C. maculata & PAI & $\mathrm{C}_{\min }$ & 0.032 & 0.029 & 0.797 & a & \\
\hline P. acerifolia & PAl & $\mathrm{C}_{\min }$ & -0.017 & 0.076 & 0.805 & a & $5 d$ \\
\hline U. procera & PAI & $\mathrm{C}_{\min }$ & 0.037 & 0.066 & 0.835 & a & \\
\hline C. maculata & PAD & $\mathrm{C}_{\max }$ & 0.057 & 0.182 & 0.768 & a & \\
\hline P. acerifolia & PAD & $C_{\max }$ & 0.006 & 0.336 & 0.875 & a & $5 e$ \\
\hline U. procera & PAD & $C_{\max }$ & 0.073 & 0.595 & 0.985 & $\mathrm{~b}$ & \\
\hline C. maculata & PAD & $\mathrm{C}_{\min }$ & 0.032 & 0.064 & 0.806 & $a$ & \\
\hline P. acerifolia & PAD & $\mathrm{C}_{\min }$ & -0.010 & 0.199 & 0.780 & a & $5 f$ \\
\hline U. procera & PAD & $\mathrm{C}_{\min }$ & 0.035 & 0.294 & 0.853 & $b$ & \\
\hline
\end{tabular}

*Significant differences between species are marked with different letters. 
Table 5 - $\mathrm{C}_{\min }$ values per plant compartment $(\mathrm{mm})$, and correspondent comparative importance on water storage (\%).

\begin{tabular}{lccccc}
\hline \multicolumn{5}{c}{ Mean $\mathrm{C}_{\min } \pm$ STD $(\mathrm{mm})$} \\
Tree species & Leaf & $\%$ & Woody & $\%$ & Total \\
\hline C. maculata & $0.05 \pm 0.00$ & 59.20 & $0.03 \pm 0.00$ & 40.80 & $0.08 \pm 0.01$ \\
P. acerifolia & $0.26 \pm 0.03$ & 89.70 & $0.03 \pm 0.01$ & 10.30 & $0.29 \pm 0.03$ \\
U. procera & $0.33 \pm 0.04$ & 87.20 & $0.05 \pm 0.01$ & 12.80 & $0.38 \pm 0.04$ \\
\hline
\end{tabular}

This article is protected by copyright. All rights reserved. 

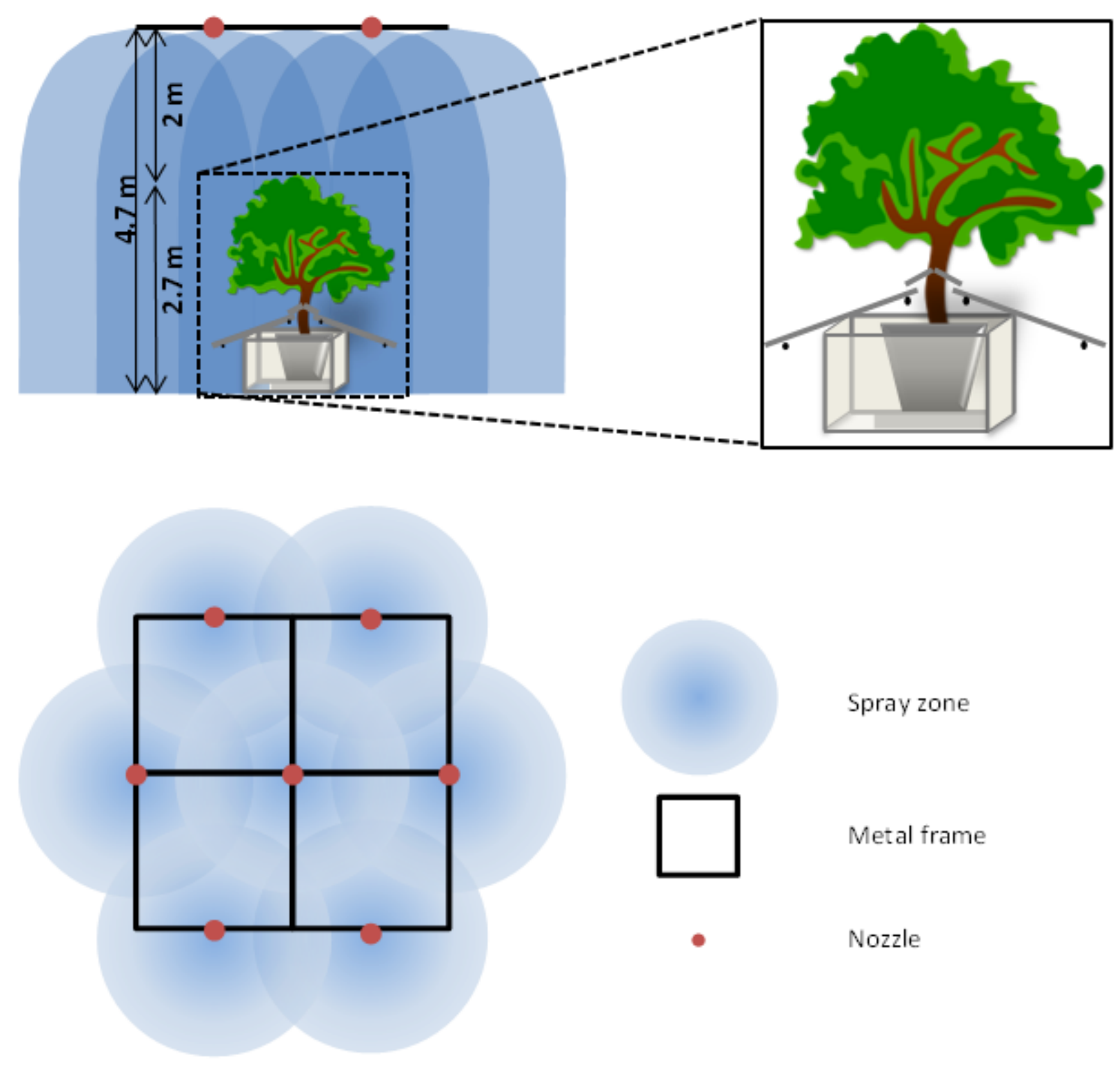

HYP_13255_F1.tif

This article is protected by copyright. All rights reserved. 


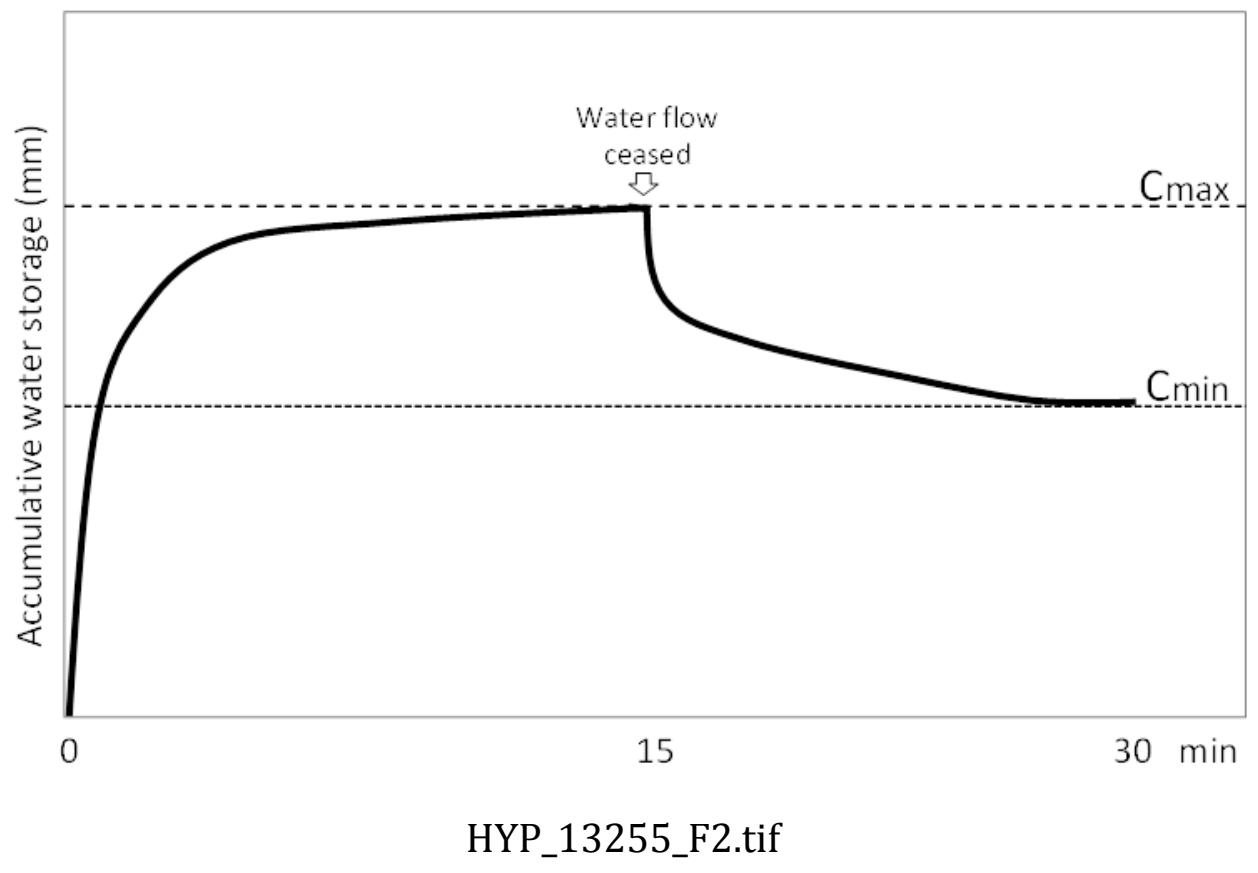

This article is protected by copyright. All rights reserved. 
(a)

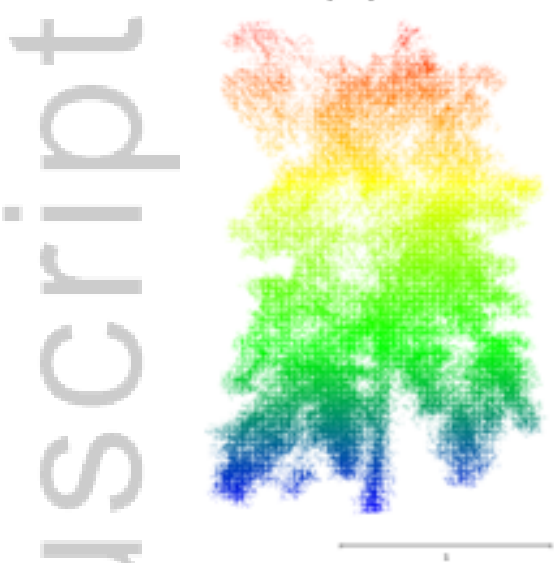

$\frac{D}{0}$
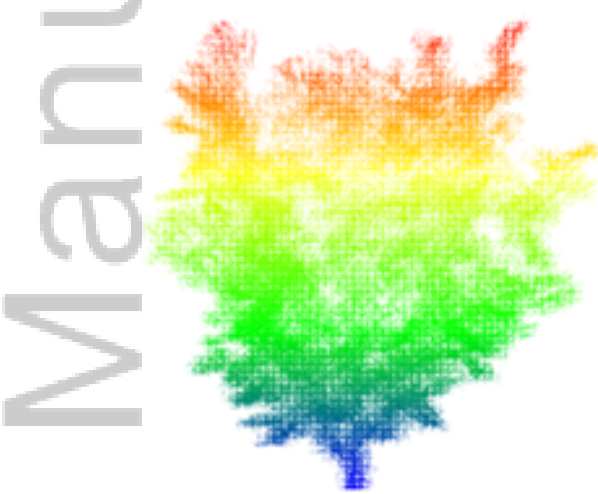

ᄂ
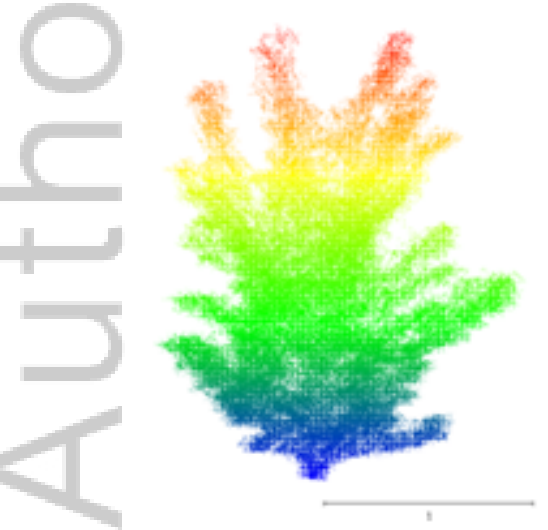

(b)
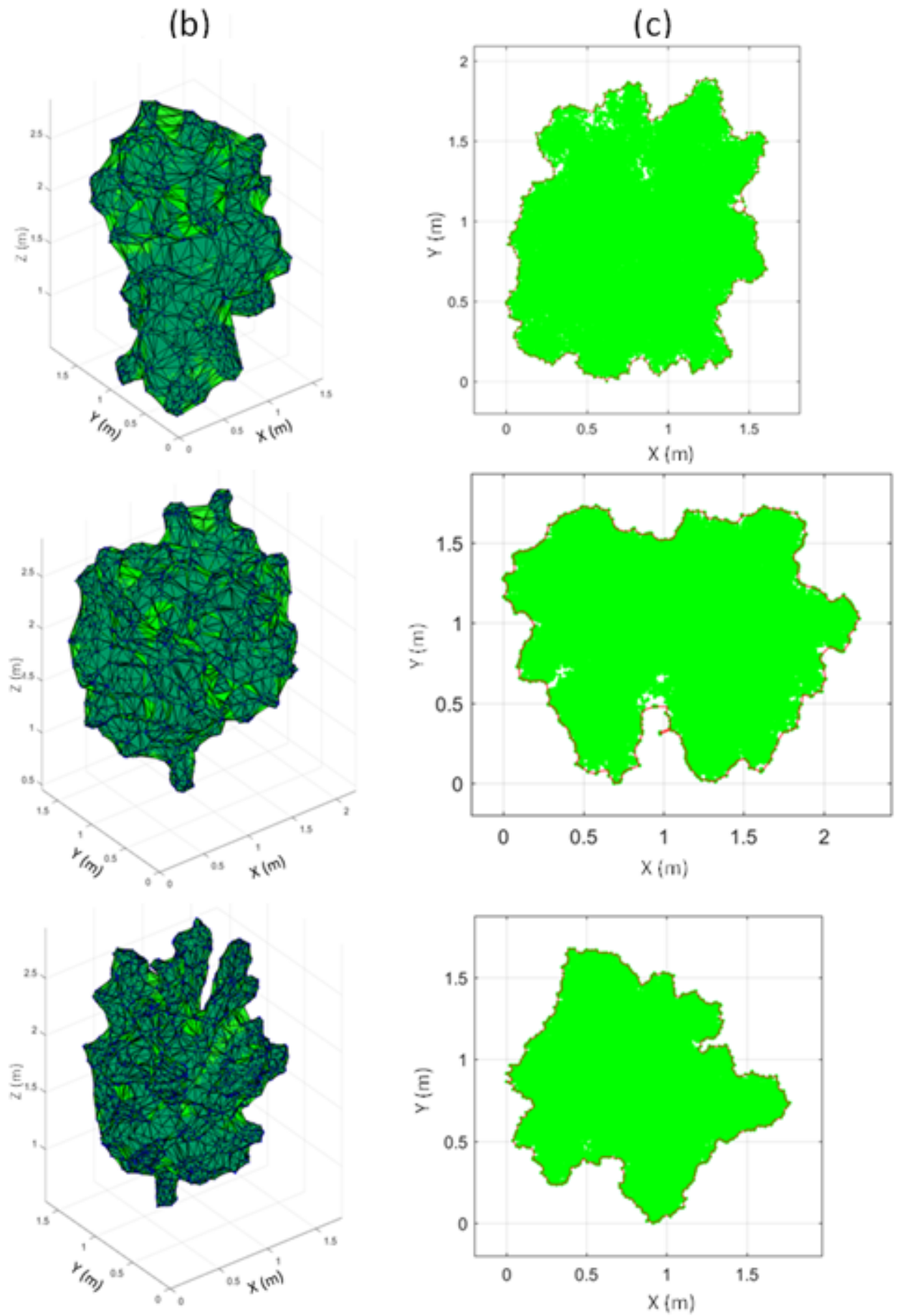

HYP_13255_F3.tif 

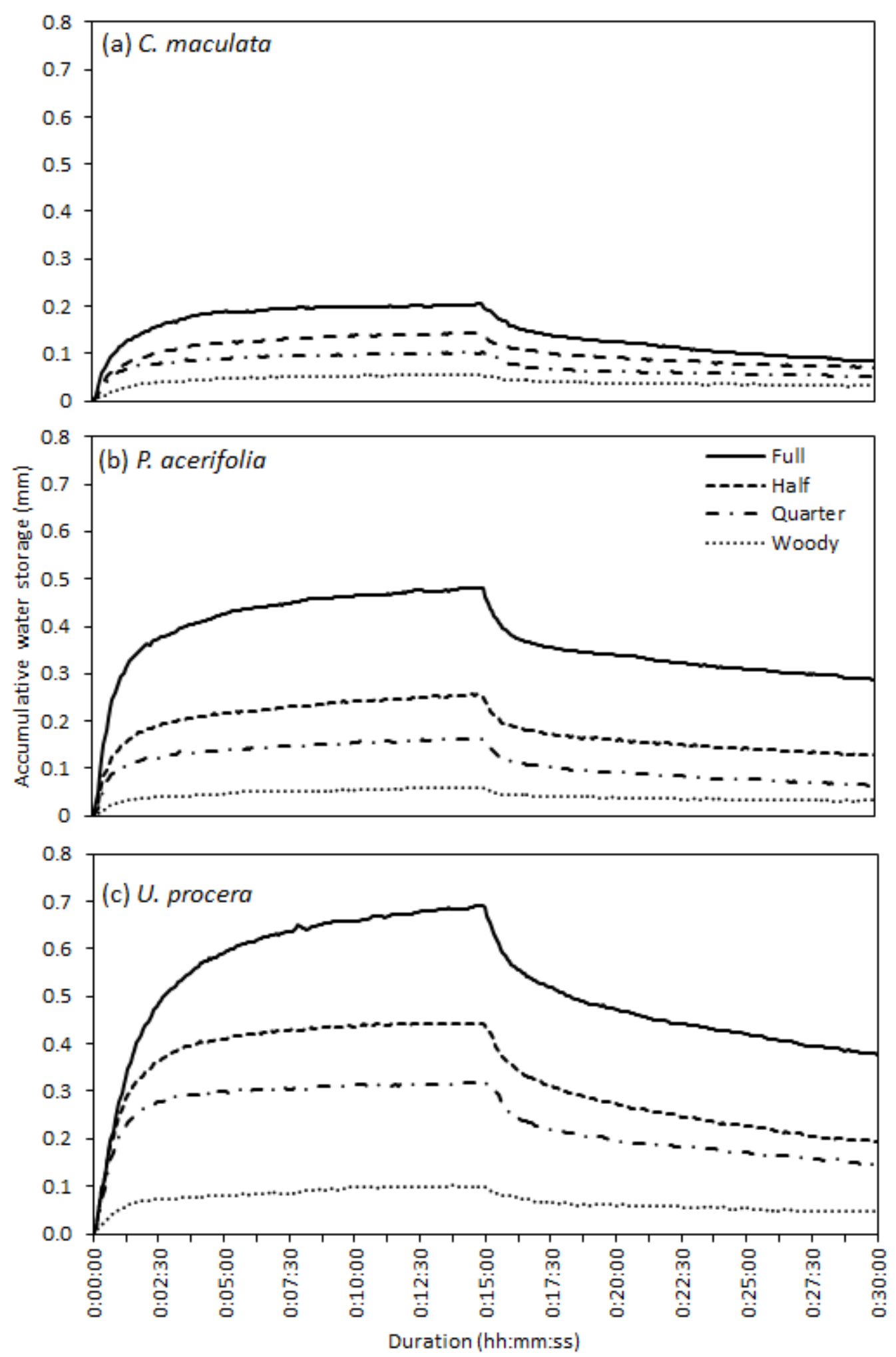

HYP_13255_F4.tif

This article is protected by copyright. All rights reserved. 

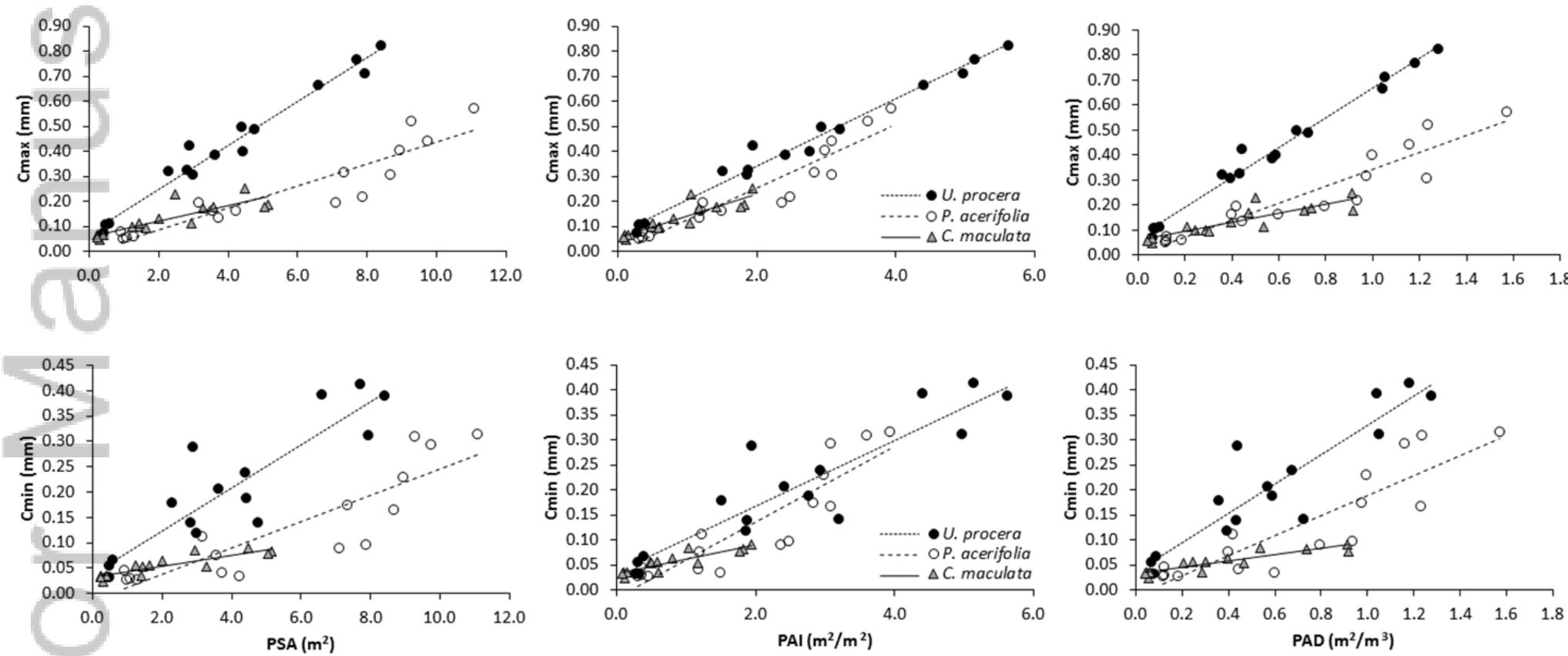

HYP_13255_F5.tif

This article is protected by copyright. All rights reserved. 


\section{University Library}

\section{- M M N E R VA A gateway to Melbourne's research publications}

Minerva Access is the Institutional Repository of The University of Melbourne

Author/s:

Baptista, MD;Livesley, SJ;Parmehr, EG;Neave, M;Amati, M

Title:

Variation in leaf area density drives the rainfall storage capacity of individual urban tree species

Date:

2018-12-15

Citation:

Baptista, M. D., Livesley, S. J., Parmehr, E. G., Neave, M. \& Amati, M. (2018). Variation in leaf area density drives the rainfall storage capacity of individual urban tree species. HYDROLOGICAL PROCESSES, 32 (25), pp.3729-3740. https://doi.org/10.1002/hyp.13255.

Persistent Link:

http://hdl.handle.net/11343/284716 